\title{
An Exploration of English Teaching for Mechanical Engineering from the View of Meta- cognitive Strategy Based on Multimedia Network
}

\author{
http://dx.doi.org/10.3991/ijet.v11i02.5269 \\ Wenting Ma \\ Luoyang Institute of Science and Technology, Luoyang, Henan, China
}

\begin{abstract}
The teaching model based on Multimedia network is proposed to improve the efficiency and effect of mechanical English learning, the advantages of computer-assisted learning is analyzed. By means of comparing the results of the experimental teaching model, conclusions are drawn that the experimental type (ET) can stimulate students' motivation much more than the control type (CP) can do. To elaborate the theoretical foundations of both task-based language teaching (TBLT) and computer assisted language learning (CALL) for mechanical engineering students, it shows the necessity and feasibility of TBLT based on Multimedia-Network for mechanical English. A teaching model for mechanical English is constructed which includes an experimental research in its application in teaching mechanical engineering students. The result of the experiment proves that the taskbased teaching model based on multimedia network changes the students' passive attitude in traditional teaching process and makes them more active in the class. In this case students' interest and creativity are stimulated and their autonomous learning ability can be trained.
\end{abstract}

Index Terms-English teaching; mechanical engineering; Meta-cognitive strategy; Computer assisted language learning; Multimedia network

\section{INTRODUCTION}

With the rapid development of computer and Internet across China, all areas of education are undergoing a huge revolution. Especially, the use of multimedia and the Internet in English teaching for mechanical engineering is gaining popularity. The pioneers are always seeking to integrate the new information technology into the new curriculum. The application of media in the colleges has been a common practice for a long time. For example, VCRs, the tape recorders, satellite TV, and some other Medias have all been introduced into the classrooms for mechanical engineering English learning. In modem times the use of computer technology has attracted the attention of education community. Especially in recent decades, with the advent of the Internet, the application of media technology is very prevalent. Even the teachers and learners know how to make full use of media technology. There is no doubt that the computers and the Internet will be potential to benefit to language learning and teaching $[1,2]$. However, the use of computer and the Internet is still neglected by some English teachers in China. They either regard it as a waste of time or treat it as a funny game. Once in a while, they just display colorful images or interesting movies for relaxation in the multimedia classroom, yet the professional linguistic contents are seldom associated. Moreover, students sit silently in front of computer screen clicking mouse and watching it in a passive way. Both the teachers and the students do not realize the importance and necessity of adopting computer and the Internet in mechanical engineering English teaching.

The significance of the study mainly lies in the following aspects: 1) with the aid of multimedia and network, both the teaching efficiency and learning efficiency of mechanical engineering English can be greatly improved. The teaching model based on the Multimedia-Network will help students gain amount of information in a short period of time. 2) The TBLT method may foster students' learning autonomy and stimulate their interest. The traditional class of ESP under a long period of domination by grammar-translation method may be very dull. The newlyadopted teaching method provides students different learning strategies. 3) Teachers can benefit from both TBLT and Multimedia-Network teaching methods in mechanical engineering English teaching. By applying the new teaching model, the teachers' burden can be reduced to a great degree, and they may make some adjustments on teaching methods in order to optimize their teaching.

The prevailing opinion of multimedia technology in language learning is that multimedia shows colorful images and arouses learners' interest for a short time but provide little help in improving the score of examinations. Some university teachers who fear that they may be replaced by Multimedia-Networks are unwilling to apply the Multimedia-Network technology in their teaching. Actually, the multimedia includes such elements as text, graphics, sound, videos and so on. For teachers, that relieve them from mechanical introduction. For students, they inspire them to learn mechanical English more enthusiastically, supplies them with a more authentic learning environment and provides them a more understandable learning background [3]. All these goals are pursued by both teachers and students. Taking the teachers' goals and students' needs into consideration, the purpose of the study is to find a new teaching model in English teaching to improve professional language competence $[4,5]$. The author points out that it is possible and necessary for the integration of TBLT and Multimedia-Network in mechanical engineering English teaching.

\section{IMPACT OF ATMOSPHERIC CONDITIONS ON THE ACCURACY OF MONITORING DATA}

Computer-Assisted Language Learning (CALL) is nowadays used routinely in English teaching. CALL is a 
PAPER

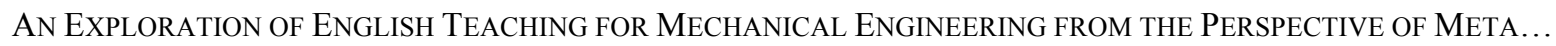

cross-disciplinary science and its closely related to the development of computer technology and the theories of applied linguistics. Since 1960s, the computer had been put into use in language learning. Its nearly50-years history that includes roughly three main periods: the behaviorist CALL period, the communicative CALL period and the integrative CALL period. Each period is based on a certain level of technology. Meanwhile, each period corresponds with a certain pedagogical approach. Behaviorist CALL can be considered as a sub-component of the broader field of CAI (computer-Assisted Instruction). In 1950s, B.F. Skinner started this movement by advocating the use of teaching machines for individualized instruction. At that time, the behaviorist CALL was based on the Stimulus-Responds theory. It argued that the whole process of learning was controlled by reinforcement or reinforcing stimulus. If people could improve the control over or the overt stimulus upon the reinforcement of learning, the learning would be achieved. Informed by the behaviorist learning model, CALL programs of this phase featured repetitive language drills, referred to as "drill and practice" or "drill and kill". In the paradigm, the computer was regarded as a mechanical tutor who never grew tired to deliver instructional materials to the student. The bestknown as well as the largest CAI system of this phase was the PLATO system developed by the Illinois University. It ran on its own special PLATO hardware, including a central computer and 4000 terminals. PLATO system provided more than 6000 series of CAI programs about over 100 courses. In the late 1970 s and early 1980 s, with the creation of PC computer, the research of CALL was improved and gradually replaced by the communicative CALL. Network diagram is as depicted in Figure 1.

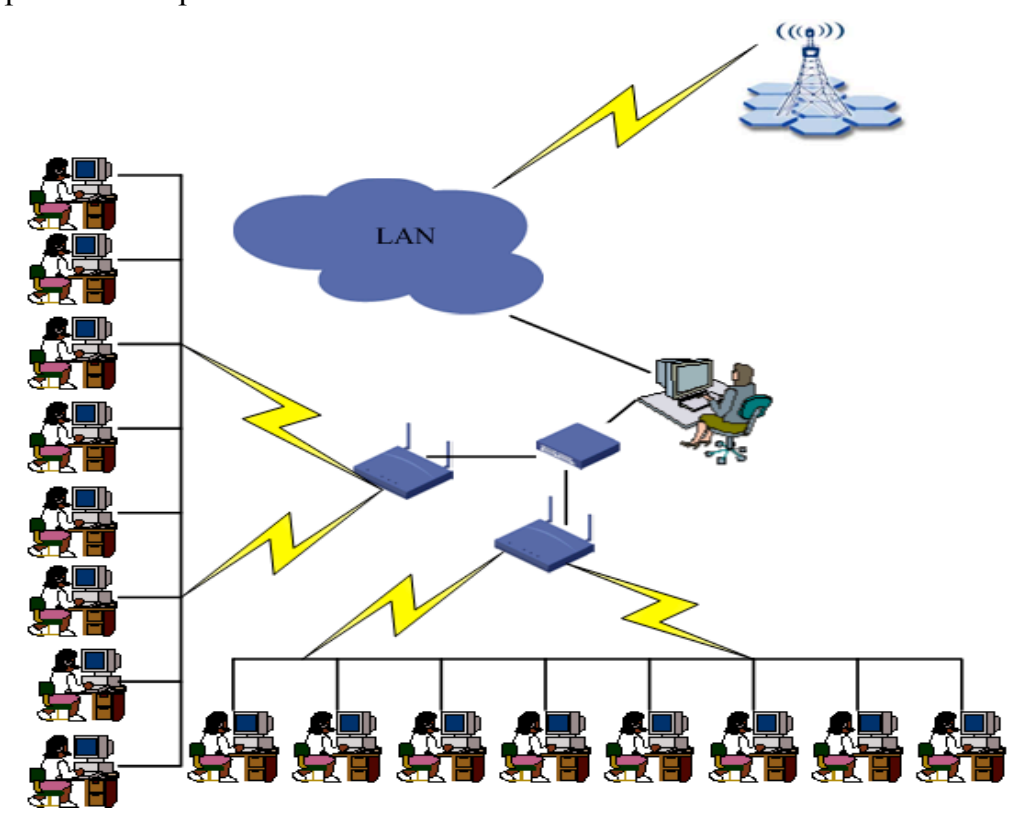

Figure 1. Multimedia-Network structure

The personal computers provided greater possibilities for individualized CALL activities. In the early 1980s, due to the decline of behaviorist CALL and the instruction of microcomputers, new computer technology and new teaching method put CALL into the communicative CALL period. The communicative CALL was conceived on the base of communicative theory which was the mainstream of linguistics in the 1970s and 1980s. It advocated that learning was a process of discovery, expression and development. The professional language teachers should not only teach students the specified linguistic knowledge but improve their communicative competence, strategic competence and interpretive strategies [6]. In 1984, the major advocate of the approach John Underwood proposed "Premises for Communicative CALL". The communicative CALL focused more on using forms rather than forms themselves. It stressed that teachers should teach grammar implicitly rather than explicitly, allow and encourage students to generate original utterances rather than just manipulate prefabricated language.

The essence of the communicative CALL is to create a communicative language learning environment to stimulate learners' motivation in the process of learning. Although the communicative CALL is superior to the behav- iorist CALL, there are also some disapproval voices. Some educators pointed out that during this period the computer was making greater contribution to marginal rather than central elements of the professional language learning process. So they sought new ways to teach in a more integrative method which could integrate various aspects of language learning process.

\section{STIMUlating The LEARNING Motivation IN NETWORK ENVIRONMENT}

In the process of learning foreign language in the network environment, the teachers play some important roles of the organization, guidance, consultation, and evaluation. They should make full use of these functions to stimulate the students' learning motivation through each teaching steps to improve the effect of network-based language teaching. In detail, they should do: In the process of learning mechanical engineering English in the network environment, the teachers play roles of guidance and consultation. The guidance and consultation of the students could promote them to study, stimulate their learning motivation and participating into the study. However, the effective premise of the stimulating strategies is that the teachers should fully understand the condition of the stu- 
PAPER

An ExPloration of English Teaching for MechaniCAl EngineERING From the Perspective of Meta...

dents, so that they could, under the proper help of the teachers, master the suitable learning strategy [7]. The conditions of the students include the age of the students, the learning background, the level of mechanical engineering English, the attitude to the foreign language learning, cognitive style and so on.

Giving feedback is the most essential step of networkbased language learning, which plays the effect of remedial, strengthening and regulation. According to the difference of the information transfer mode in the networkbased language learning, there are two kinds of feedback given by the teachers: one is asynchronous feedback, the other one is synchronous feedback. Asynchronous feedback refers that there is no time delay in the communication between the teachers and the students; when the teachers or the students send information to the other side, they can receive the information immediately and reply it right away. Synchronous feedback refers that there is a time difference in the communication between the teachers and the students. When one side send information to the other-side, the other-side cannot receive the information immediately and cannot reply it right away. Giving timely feedback from the students is the necessary condition for the students to learn continuously and efficiently.

Network-based language teaching is a new teaching approach. For most of the teachers, the network environment is a relatively unfamiliar environment. The teachers must master enough network strategies and skills in order to provide the students with teaching service, encourage and evaluation in this kind of complicated and strange environment. As a result, the teachers could guarantee that the learning process is going smoothly and efficiently and the students would not lose the learning motivation.

The process of efficient learning is the process of interaction between the students and the learning materials. In the process of learning, the teacher undertakes the functions of consultation; receive feedbacks, modifying the learning materials and so on. Therefore, we need from the teachers and the students, these two aspects to consider the design of the learning materials. From teachers' point of view, the network learning materials should reduce the teachers' workload in order to stimulate the teachers' motivation of employing this new teaching method. That would be convenient for the teachers to arrange the teaching time flexibly or get some other benefits. From students' point of view, the network learning materials should let the students get the feeling of what this new learning method could give them, such as, better learning experience, better learning performance and more independent learning opportunities.

Generally speaking, learning environment refers to the site where the students do the exploration and learning. This kind of saying emphasizes on the physical characteristics of the learning environment of the students. The writer thinks that the network-based language learning environment could be seen as an environment which is the combination of the real hardware environment and the virtual software environment [8]. When the teachers are designing the network learning environment, they must make a comprehensive consideration of the designing process. They need to research all of the elements which could have different influences on the motivation of the students, so that, they could optimize the network learning environment and improve the efficiency of the resource utilization, and stimulate the students' motivation in the highest degree $[9,10]$.

\section{EXPERIMENTAL TEACHING MODEL}

The thesis consists of three kinds of experimental instruments: Test, Classroom Experiment and Interview. All of these instruments are put to use in order to prove the necessity and efficiency of TBLT, based on MultimediaNetwork in mechanical engineering English teaching. Test is an effective tool which can inspect the different teaching effects with the different teaching methods. The study carried on pre-test and post-test respectively following Experimental Type (ET) and the Control Type (CT), before and after the classroom experiment.

Aim of the tests: The function of the tests is to guarantee the comparability of the variable in ET and CT. Although the two selected classes' results in the final examinations are relatively close to each other, we still can't affirm that the English level of the two classes is identical before the experiment. Only after comparing the disparity of the pre-test and post-test, we can determine whether there are significant differences. In this way it is proved that the TBLT method based on Multimedia-Network in the ET is more effective than the traditional teaching method in the CT. Content of the tests: The study is to research whether the new teaching model adopted in mechanical engineering English teaching is superior, so the content of the tests are closely related with the teaching material. Listening, speaking, reading and writing skills in mechanical engineering English are emphasized simultaneously.

In the $\mathrm{CT}$, the teacher adopts the traditional teaching method. 3P paradigm (presentation, practice and production) is mainly applied. During the teaching process, the teacher takes the dominant position in the classroom. Firstly, she presents the topic of grinding with some pictures and asks students to learn the new words. Then she explains the paragraphs in details one by one. The analysis of sentence structures and meanings are emphasized. Finally, the exercises are discussed in the whole class and students are demanded to translate similar articles about the topic. During the observation, the author finds that most of the students in the CT are passively stand out to answer questions. They always take notes by themselves. The classroom atmosphere is dull.

The pre-task is always completed before the class. Within the context of CALL, one of the important aspects of teaching is, planning for teachers to design an attractive PPT which can greatly improve the teaching efficiency. The content of PPT should include professional background information, introduction of the technical terms, discourse analysis, rhetorical devices and so on. A large part of these materials may be obtained from Internet. For example, teachers can take advantage of hypertext technology to explain the technical terms and rhetorical devices in the text. This text involves the issue of grinding. There are lots of online graphic and audio-visual materials which can give students visual impact. Hence, the students' interest and motivation can be enhanced. On the other hand, the teachers can arrange some tasks in advance orally or through e-mail and require students to carry out the tasks in pairs or group. With respect to this text, the teachers divide the whole class into five groups. Each group will have a group leader who is responsible for the arrangement and organization of activities. The 
teachers give each group a topic according to the teaching content. Students can collect relevant information about the topics from Internet and make a discussion in the group. Finally their achievement will be shown in a PPT, which is presented and explained by a representative chosen in that group.

Itis essential for students to preview the whole text. The students will be familiar with the technical terms and the structure of the text with the means of going through the whole text. After generally understanding the text, students begin to collect the most valuable information from the all-encompassing Internet. In the panel discussion the group should accumulate and analyze all the information from all team members. An imaginative and creative PPT can be finally finished with the efforts of the whole group members.

Meanwhile in the class period, the teacher will firstly give some instructions. A good lead-in of an article, which must be interested and attracted by students, is half successful teaching. Teachers can design the effective lead-in with the help of Internet.

\section{RESUlts AND ANALYSIS}

Data collection is a very important work in experiments, and it is the foundation of analyzing the experi- ments' results. In this experiment, the data collected by the author mainly include: 1) the results of the pre-test for all the subjects at the beginning of the experiment; 2) the results of the post-test for students in the ET and CT at the end of the experiment. The function of the pre-test is to see whether the English level of the students in the ET is equivalent to that of the students in the CT. The function of the post-test is used to compare the differences of the results between ET and CT after the application of TBLT and CALL in the teaching of ET. The two tests are completed by the students carefully under the same teacher's supervision. The results of the two tests can be shown in Table1.

Data analysis is the most important component in an experimental research. In order to enhance the objectivity and validity of the experiment, the author used the SPSS 10.0 software to analyze the collected data in the research. The hypothesis of the research is that TBLT within the CALL context is a more effective method for teaching and learning mechanical engineering English than traditional teaching method. In order to prove the hypothesis, the author adopted TBLT within CALL context in ET and traditional teaching method in CT. All the students were taught by the same teacher with the same teaching material in mechanical engineering English.

TABLE I.

PAIRED SAMPLE STATISTICS

\begin{tabular}{|c|c|c|c|c|c|c|}
\hline & & Mean (\%) & $\mathbf{N}$ & SD & Mean standard error & Sig \\
\hline \multirow{2}{*}{ Pair 1} & Pre-test CT & 79.37 & 42 & 7.21 & 1.92 & \multirow{2}{*}{0.17} \\
\hline & Pro-test ET & 83.01 & 42 & 6.52 & 1.68 & \\
\hline \multirow{2}{*}{ Pair 2} & Pre-test CT & 80.15 & 42 & 7.16 & 1.85 & \multirow{2}{*}{0.13} \\
\hline & Pro-test ET & 83.11 & 42 & 6.33 & 1.53 & \\
\hline \multirow{2}{*}{ Pair 3} & Pre-test CT & 80.25 & 42 & 5.71 & 1.42 & \multirow{2}{*}{0.08} \\
\hline & Pro-test ET & 84.41 & 42 & 5.26 & 1.29 & \\
\hline \multirow{2}{*}{ Pair 4} & Pre-test CT & 79.19 & 42 & 5.52 & 1.37 & \multirow{2}{*}{0.06} \\
\hline & Pro-test ET & 84.63 & 42 & 4.88 & 1.06 & \\
\hline \multirow{2}{*}{ Pair 5} & Pre-test ET & 78.65 & 42 & 8.25 & 2.21 & \multirow{2}{*}{0.51} \\
\hline & Pro-test CT & 79.21 & 42 & 7.88 & 2.02 & \\
\hline \multirow{2}{*}{ Pair 6} & Pre-test ET & 77.62 & 42 & 8.69 & 2.33 & \multirow{2}{*}{0.48} \\
\hline & Pro-test CT & 81.56 & 42 & 7.71 & 1.94 & \\
\hline \multirow{2}{*}{ Pair 7} & Pre-test ET & 80.54 & 42 & 7.94 & 2.15 & \multirow{2}{*}{0.39} \\
\hline & Pro-test CT & 81.11 & 42 & 7.92 & 2.11 & \\
\hline \multirow{2}{*}{ Pair 8} & Pre-test ET & 81.24 & 42 & 7.81 & 1.99 & \multirow{2}{*}{0.27} \\
\hline & Pro-test CT & 79.45 & 42 & 6.93 & 1.78 & \\
\hline
\end{tabular}

TABLE II.

CHANGES IN LEARNING STRATEGIES

\begin{tabular}{|l|c|c|c|c|}
\hline \multirow{2}{*}{} & \multicolumn{2}{|c|}{ ET } & \multicolumn{2}{c|}{ CT } \\
\cline { 2 - 5 } & Pre-test & Pro-test & Pre-test & Pro-test \\
\hline Mean & 79.51 & 82.74 & 79.74 & 80.33 \\
\hline SD & 5.98 & 6.51 & 5.77 & 6.09 \\
\hline
\end{tabular}

TABLE III.

PAIRED SAMPLES STATISTICS

\begin{tabular}{|c|l|c|c|c|c|}
\hline \multicolumn{2}{|c|}{} & Mean & N & SD & Std. Error Mean \\
\hline \multirow{2}{*}{ Pair1 } & Pre-test ET & 79.51 & 42 & 5.98 & 0.81 \\
\cline { 2 - 6 } & Pro-test ET & 82.74 & 42 & 6.51 & 1.03 \\
\hline \multirow{2}{*}{ Pair2 } & Pre-test CT & 79.74 & 42 & 5.77 & 0.78 \\
\cline { 2 - 6 } & Pro-test CT & 80.33 & 42 & 6.09 & 0.96 \\
\hline
\end{tabular}


the tables reveal that in the pre-test the mean score of the ET and CT is respectively 79.51 and 79.74, SD is 5.98 and 5.77. These statistics make it credible that there is no significant difference between students in the ET and those in the CT in the test. The two classes start nearly from the same point. However, from the statistics in the third table we find after the experiment there is notable difference between students in the ET and in the CT. For the ET, Mean=82.74, $\mathrm{SD}=6.51$. For the $\mathrm{CT}, \mathrm{Mean}=80.33$, $\mathrm{SD}=6.09$. The mean difference between the two classes is 2.52. From another perspective, for the CT, the mean score of the two tests is respectively 79.74 and 80.33 . There is little difference of mean score between pre-test and post-test $(0.02)$. In the two tests on CT, $t=-0.142$ $(|t|<2)$ and $p=0.853>0.05$. So the progress does not reach the statistic requirement. There is not any obvious in the CT but for the ET, the mean score of the two tests is respectively 79.51 and 82.74 . The mean difference between the pre-test and post-test is 3.02. Furthermore, in the two tests on ET, $t=-6.301(|t|>2)$ and $p=0.000<0.05$. Both the mean difference and test shows that the progress has achieved the remarkable and significant level.

Just mentioned in the last chapter, the author took part in the class as an observer once in a while during the whole process of the experiment. From this experience, the author found some differences of students' performance in the ET and in the CT. The teaching time for each unit is different. Due to the application of multimedia and network in the ET, both teachers and students finish the tasks in the Multimedia-Network environment in which they can search the useful information in advance and show them in a more convenient way. The teachers can transfer a large amount of impressive information in a period of limited time. The roles of both teachers and students are changed. According to the observation in the $\mathrm{CT}$, time for the teacher is about $80 \%$ and for students is only $25 \%$. In comparison, time for the teacher is about $30 \%$ and for students is $70 \%$ in the ET. We can see that in the traditional approach, the teachers play the dominant role and students always perform passively. So the atmosphere is dull in the class. However, in the new teaching approach, the teachers play the role of a supervisor, who organizes the classroom activities according to arrangement of various meaningful tasks. Students' participation in every kind of tasks of even pre-class and post-class, and they cooperate and exchange with each other. In this way students will truly become the masters of their study.

The time that students spend after class is different. Most students in the CT just spent a little time to read through the whole texts. It shows that students' motivation and learning desire in the ET is stimulated. Students' learning attitude is discrepant. In the CT, the teacher spoon-feeds the students. The students perform passively and most of them take notes by themselves. The situation in the ET is quite different. The students are actively involved in the discussion and express their own opinions. The tasks exhibit their innovation and team spirit. It's not suspicious that the students must develop towards the direction of independent exploration and self-thinking.

\section{CONCLUSIONS}

TBLT gives the students more opportunities for them to plunge into the task practice activities in a meaningful response to the limitations of some original English teaching methods in the traditional teaching curriculum. The teacher is the realistic communicative motivator, who designs appropriate tasks for the students to express genuine information; sample information from the Internet so TBLT is realistic and meaningful. To encourage the students to use English to communicate with the other students, the students' motivation and interest in the process of group working for English Learning task could be stimulated much greater. The preparing activities such as brainstorming and pre-task planning are also used so that the students could create some new ideas on what to say and some expressions and suggestions on how to express their ideas and creativities, to express their ideas and creativities.

\section{REFERENCES}

[1] Zhu Y Q, “Applications of the situation-task approach to business English teaching in vocational technology colleges, based on ESP theories." World Transactions on Engineering and Technology Education, vol. 12, no.1, pp.89-93, March 2014.

[2] Hutchins, J. "Current Commercial Machine Translation Systems and Computer-based Translation Tools: System Types and Their Uses”. International Journal of Translation, vol.17, no.1, pp.5-38, 2005.

[3] Koehn, P. "A Process Study of Computer-aided Translation". Machine Translation, vol.23, no.4, pp. 241-263, November 2009. http://dx.doi.org/10.1007/s10590-010-9076-3

[4] Marenzi, Ivana, and Deirdre. Kantz. "ESP Course Design - A Multiliteracies Approach." IEEE 13th International Conference on Advanced Learning Technologies (ICALT),Beijing, pp:221223, July 2013.

[5] Jie Shi, "ESP: A needs-oriented approach for scientific English education." Proceedings of the 2013 International Conference on Advanced Mechatronic Systems, Luoyang, pp.400-405, August 2013. http://dx.doi.org/10.1109/ICAMechS.2013.6681816

[6] Hidri Sahbi, "Developing and evaluating a dynamic assessment of listening comprehension in an EFL context," Language Testing in Asia, vol.4, no.1, pp. 4-9, 2014. http://dx.doi.org/10.1186/22290443-4-4

[7] Duan, Guoxiang. "A college English teaching model based on web-platform." 2011 International Conference on Multimedia Technology, Hengzhou, pp. 4745-4747, 2011. http://dx.doi.org/10.1109/ICMT.2011.6002208

[8] Alabbad, A. M. "Interactive computer/network-based program for teaching English as a foreign language in the elementary levels in Saudi Arabia." International Conference Multimedia Computing and Systems, Ouarzazate, pp.1-4, 2011. http://dx.doi.org/10.1109/icmcs.2011.5945699

[9] Carless, David. "Implementing task-based learning with young learners." English Language Teaching Journal, vol.56, no.4,pp.389-396,2002. http://dx.doi.org/10.1093/elt/56.4.389

[10] Gold, Sanford. "A constructivist approach to online training for online teachers." Journal of Asynchronous Learning Networks vol.5,no.1,pp.35-57,2001.

\section{AUTHOR}

Wenting $\mathrm{Ma}$ is a lecturer in School of Foreign Languages, Luoyang Institute of Science and Technology, Luoyang, Henan, 471023, China. Her research interests include English teaching methodology, ESP teaching and translation. (e-mail: emilymwt@163.com).

This work was supported by the Natural Science and Technology Research of Foundation Major Project of Henan Province under Grant (No.142400411396). Submitted 15 November 2015. Published as resubmitted by the authors 28 January 2016. 